\title{
Effects of high altitude hypoxia on left ventricular systolic time intervals in man $^{1}$
}

\author{
V. Balasubramanian, V. S. Kaushik, S. C. Manchanda, and Sujoy B. Roy \\ From the Department of Cardiology, All India Institute of Medical Sciences, New Delhi; \\ and Directorate General Armed Forces Medical Services, New Delhi, India
}

\begin{abstract}
Effects of high altitude hypoxia on systolic time intervals were examined in 34 healthy men: 20 sea level residents studied at rest and at the end of 3 minutes steady isometric (handgrip) exercise at sea level and then serially for the first 5 days and on the tenth day, at an altitude of $3658 \mathrm{~m}$, and 14 permanent residents at high altitude studied at high altitude. In the sea level residents there was a significant increase in the preejection period (PEP), abbreviation of the left ventricular ejection time (LVET), both corrected for heart rate, and prolongation of the PEP/LVET ratio at high altitude. The maximum changes were seen on days 2 and 3; these parameters tended to approach sea level control values by the tenth day. The systolic time interval values of high altitude residents were similar to the control values of the sea level residents obtained at sea level but significantly different from the changes in the sea level values seen in the first 4 days at high altitude. It thus appears that while the high altitude residents do not show any left ventricular dysfunction as determined by systolic time intervals, healthy sea level residents when exposed to high altitude hypoxia show a significant depression of the left ventricular function for at least the first 4 days. This might be a contributing factor in the genesis of high altitude pulmonary oedema.
\end{abstract}

Left ventricular systolic time intervals as indirect indices of myocardial performance have been widely used for the study of ventricular functions in patients with various forms of heart disease including acute myocardial infarction (Moskowitz and Wechsler, 1965; Weissler, Harris, and Schoenfeld, 1968, 1969; Spodick, Dorr, and Calabrese, 1969; Diamant and Killip, 1970; Perloff, Talano, and Ronan, 197I; Weissler and Gerrard, 197I). Effects of circulatory stress-tests such as dynamic and static exercise (Aronow, 1970; Pigott et al., 1971 ; Siegel et al., 1972; Lindquist, Spangler, and Blount, 1973), pharmacological intervention (Weissler et al., 1965; Weissler and Schoenfeld, 1970; Buyukozturk, Kimbiris, and Segal, I97I), and alteration of preload (Khanna et al., 1973) on the systolic time intervals have also been extensively reported. However, the response of the systolic time intervals to high altitude hypoxia in man has not been well defined. Kowalsky and Anthony (1972) have reported the effects of acute hypobaric hypoxia in 26 normal healthy men at simulated

Received 14 August 1974.

${ }^{1}$ In part supported by Indian Council of Medical Research, New Delhi, India. altitudes of 4572 and 5486 metres for periods of ro minutes, which they claimed was enough time to allow for a measure of equilibration. This study could hardly be equated to exposure to high altitude hypoxia either for a period of a few days or for a life time. The present study was designed to evaluate the effects of more prolonged exposure to high altitude hypoxia on systolic time intervals in normal healthy sea level residents when suddenly removed to high altitude and compare these observations with those of permanent residents at high altitude.

\section{Subjects and methods}

Systolic time intervals estimated in $\mathbf{3 4}$ healthy male volunteers form the basis of this clinical report. Twenty of them were plainsmen who were first studied at sea level, then at an altitude of 3658 metres for the first 5 days and on the tenth day after arrival at this altitude. Fourteen permanent residents of high altitude whose forbears had lived there for three generations and who had never been to the plains were also studied on two different occasions at the high altitude. The mean age of the sea level residents was 26.5 years and that of high altitude residents was 27 years. All subjects were scrupulously screened to exclude any disease. 
All measurements were recorded in the morning in a fasting state in a semidarkened room kept at $30^{\circ} \mathrm{C}$. The subjects were not allowed to smoke and had ingested no drugs during the entire study. The nature of the procedures had been explained to them beforehand. The blood pressure was measured in the recumbent position. Recordings were made with the subject in a supine position, with the head slightly raised by one pillow, during quiet normal breathing.

Simultaneous tracings of the electrocardiograms, phonocardiograms, and carotid artery pulsations were recorded using a Sanborn four-channel direct writing polygraph at a paper speed of $100 \mathrm{~mm} / \mathrm{s}$. The electrocardiogram was obtained from a routine or augmented limb lead wherever the earliest component of the QRS complex was clearly seen. An Electronics for Medicine microphone (A.I6I) was placed over the praecordium to the left of the sternum in an optimal position for recording the high frequency signals of the first and second heart sounds at a filter range of 40 to $200 \mathrm{~Hz}$. The carotid artery pulsations were recorded using a funnel-shaped pick-up attached to a Statham P23AA manometric pressure transducer by a $20 \mathrm{~cm}$ rubber tube with an internal diameter of $3 \mathrm{~mm}$. A minimum of 15 complexes was recorded for measurements from to consecutive cardiac cycles.

Isometric hand-grip exercise was given by means of a balloon dynamometer. The subject was required to grip at 30 per cent of his maximum voluntary contraction for a duration of 3 minutes. The hand balloon dynamometer was held at arm's length and the arm supported on a rest. Recordings were then repeated at the end of 3 minutes while the patient was stil performing the handgrip. Care was taken to ensure that the subject was breathing normally during the recording (Flessas, Kumar, and Spodick, 1970). All studies both at sea level and high altitude were conducted under identical conditions by the same observers using the same equipment. Using ro consecutive complexes the following time intervals were measured.

I) Total electromechanical systole $\left(\mathrm{QS}_{2}\right)$. The interval from the onset of ventricular depolarization to the first high frequency vibration of the aortic component of the second sound;

2) $Q S_{1}$ from the earliest component of the QRS complex to the first high frequency vibration of the first heart sound;

3) Left ventricular ejection time (LVET) measured from the onset of rapid upstroke of the carotid pulse to the nadir of the dicrotic notch.

4) Pre-ejection period (PEP) from the onset of electrical activity to the beginning of left ventricular ejection was calculated by the equation

$$
\mathrm{PEP}=\mathrm{QS}_{2}-\mathrm{LVET}
$$

The averages of each of the above measurements from the ro consecutive cardiac cycles were calculated.

Indices correcting the data for heart rate were calculated using the regression equations suggested by
Lindquist et al. (1973) for resting and isometric exercise:

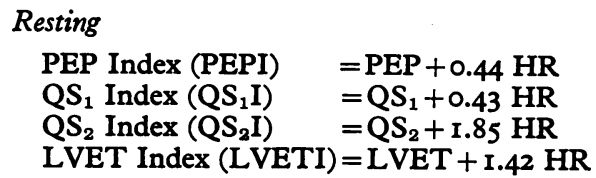

\begin{tabular}{|c|c|}
\hline $\begin{array}{l}\text { PEP I } \\
\mathrm{QS}_{1} \mathrm{I} \\
\mathrm{QS}_{2} \mathrm{I} \\
\text { LVET I }^{2}\end{array}$ & $\begin{array}{l}=\mathrm{PEP}+0.60 \mathrm{HR} \\
=\mathrm{QS} S_{1}+0.17 \mathrm{HR} \\
=\mathrm{QS} \\
=\mathrm{LVET}+\mathrm{I} .75 \mathrm{HR} \\
=\mathrm{I} .15 \mathrm{HR}\end{array}$ \\
\hline
\end{tabular}

After isometric exercise

The PEP/LVET ratio was calculated from the appropriate values uncorrected for heart rate.

Significance of difference was evaluated using the paired ' $t$ ' test.

\section{Results}

\section{Heart rate}

Response of the mean heart rate, at rest and after isometric hand grip exercise, of the 20 healthy sea level residents to high altitude is shown in Fig. I. The maximal increase is seen on the first two days after arrival at the altitude; heart rates are significantly higher $(\mathbf{P}<0.00 \mathrm{I})$ than the sea level values as well as from those of the permanent residents of high altitude.

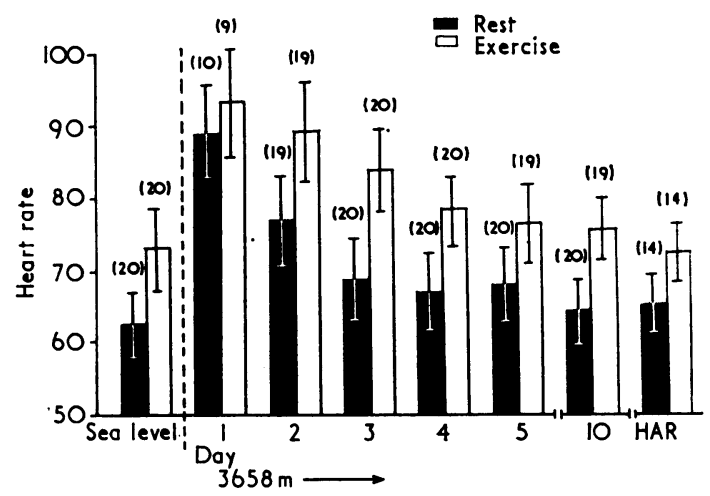

FIG. I The response of the heart rate (resting and exercise) of 20 healthy sea level residents when exposed to $3658 \mathrm{~m}$ from day $\mathrm{I}$ to 5 and on day 10 . The last two columns represent the resting and exercise heart rate of 14 permanent residents at high altitude. The values are shown here as means with standard deviations. The number in parentheses at the top of each bar represents the number of subjects studied. Data in Fig. 2, 3, and 4 are also presented in similar pattern. 
TABLE Mean values and standard deviation of $Q S_{1}, Q S_{2}$, and $Q S_{2} I$ in ms in sea level residents at sea level and at high altitude with values for high-altitude residents for comparison

\begin{tabular}{llllllc}
\hline & QS & \multicolumn{2}{c}{$Q S_{2}$} & \multicolumn{2}{c}{$Q S_{2} I$} & \\
\cline { 2 - 7 } & Basal & Exercise & Basal & Exercise & Basal & Exercise \\
\hline Sea level & 51 & 52 & 385 & 387 & 500 & 515 \\
SD & 7.4 & 9.6 & 33.2 & 20.4 & 29.3 & 15.6 \\
Day I & 45 & 50 & 331 & 329 & 489 & 493 \\
SD & 11.4 & 19.9 & 24.7 & 22.9 & 14.7 & 15.5 \\
Day 2 & 47.9 & 46 & 352 & 352 & 494 & 509 \\
SD & 11.0 & 14.8 & 36.0 & 30.4 & 33.5 & 20.7 \\
Day 3 & 47 & 50 & 368 & 366 & 495 & 513 \\
SD & 8.9 & 12.7 & 40.3 & 30.7 & 32.0 & 15.7 \\
Day 4 & 50 & 53 & 375 & 371 & 498 & 507 \\
SD & 12.5 & 14.2 & 37.6 & 27.5 & 30.3 & 20.4 \\
Day 5 & 50 & 51 & 366 & 364 & 491 & 500 \\
SD & 7.5 & 11.8 & 31.7 & 24.6 & 27.2 & 15.4 \\
Day 10 & 50 & 50 & 377 & 373 & 497 & 505 \\
SD & 9.6 & 19.9 & 30.1 & 18.7 & 25.9 & 14.2 \\
High altitude residents & 45 & 47 & 393.3 & 392.3 & 513.4 & 520.5 \\
SD & 8.8 & 12.1 & 23.7 & 24.9 & 19.1 & 21.7 \\
\hline
\end{tabular}

\section{Electromechanical time intervals}

It is apparent from the Table that $\mathrm{QS}_{1}, \mathrm{QS}_{2}$ (and also corrected for heart rate $\mathrm{QS}_{2} \mathrm{I}$ ) time intervals of sea level residents do not change appreciably at high altitude and are similar to those of high altitude residents.

\section{Pre-ejection period index (PEPI) (Fig. 2)}

Maximum prolongation of pre-ejection period index values, both resting and after static exercise, are seen on day 2 and 3 after arrival at the altitude; the resting values change from 115 to $130 \mathrm{~ms}$ and the exercise values from 137 to 154 and $158 \mathrm{~ms}$ $(\mathbf{P}<0.001)$. The values tended to approach sea level value by the tenth day. The pre-ejection period index values of the high altitude residents are similar to those of the sea level residents at sea level, but significantly different from those of sea level residents obtained at high altitude on the second and third days $(P<0.005$ and $<0.001)$.

\section{Left ventricular ejection time index (LVETI)} (Fig. 3)

Both the resting and exercise left ventricular ejection time index values are significantly shortened on all the days at the high altitude $(P<0.00 r)$. The resting and exercise sea level values of 395 and $379 \mathrm{~ms}$ decrease to 368 and $348 \mathrm{~ms}$ on day $\mathrm{I}$. Thereafter the values steadily increase up to the tenth day but are significantly lower than those obtained at sea level as well as those of the high altitude residents $(\mathbf{P}<0.001)$.

\section{PEP/LVET ratio (Fig. 4)}

The resting PEP/LVET ratio shows maximum increase on day 2 (from 0.287 to 0.370 ) and on day 3 (to 0.362 ) after which the values progressively decrease to 0.318 on the tenth day, which is still significantly increased $(P<0.005)$. The exercise value similarly shows a maximum increase on day 2 (from 0.315 to 0.403 ) and on day 3 (to 0.418 ), after

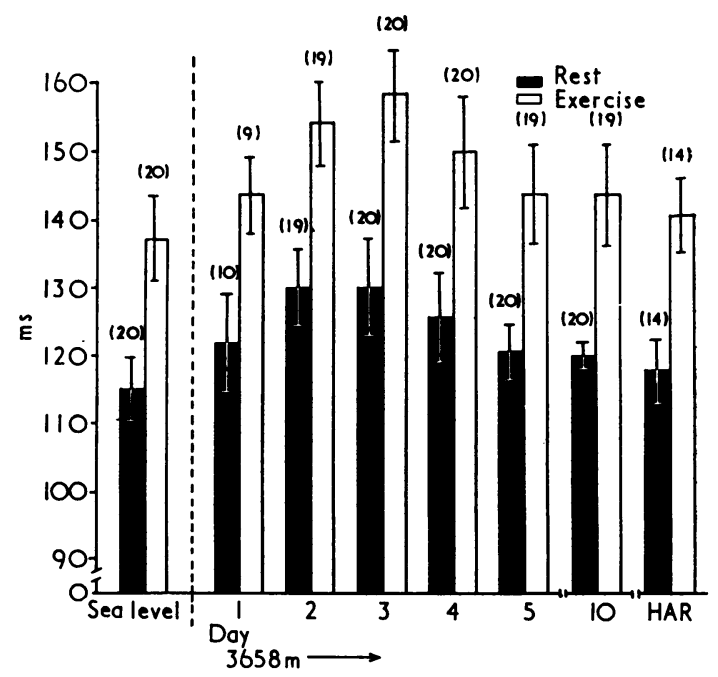

FIG. 2 Mean and standard deviation values of preejection period index (PEPI) of the same 20 healthy sea level residents and 14 high altitude residents. 


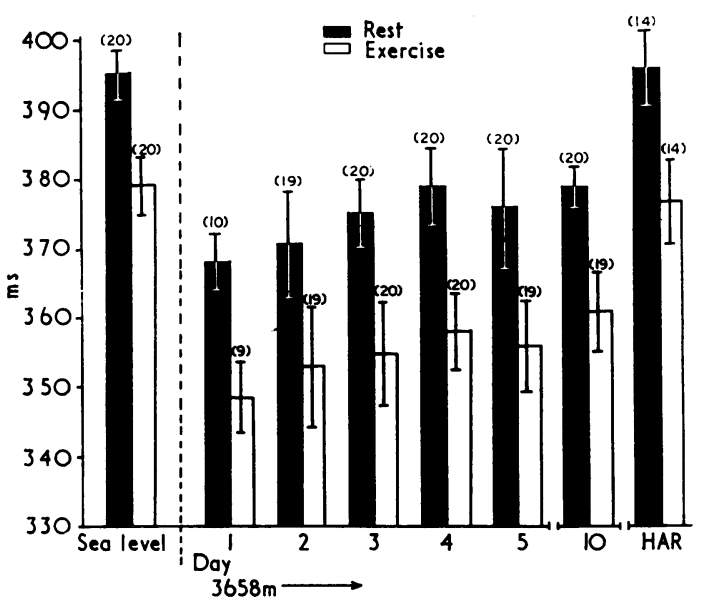

FIG. 3 Left ventricular ejection time index (LVETI) values of the same group of 20 healthy sea level residents and 14 high altitude residents.

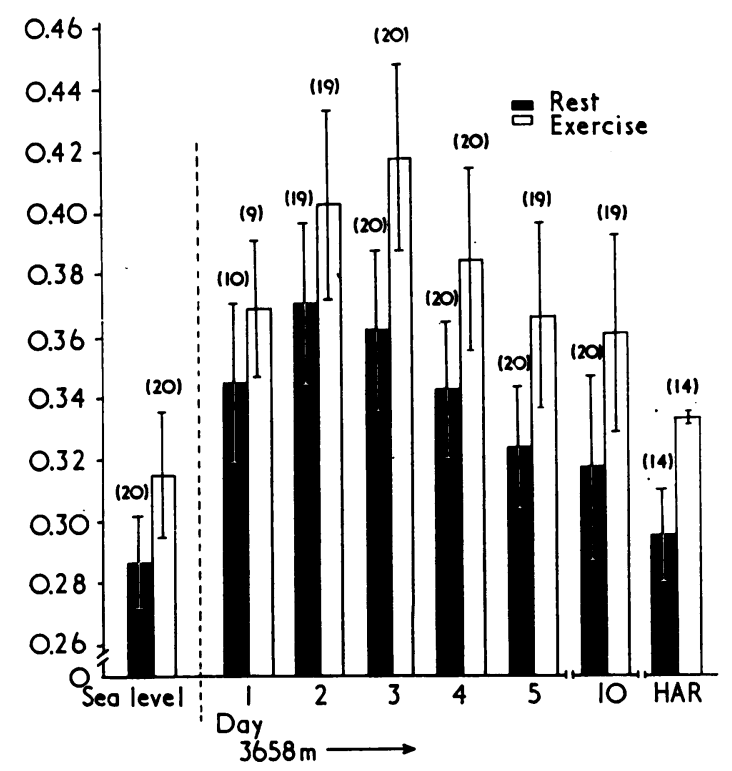

FIG. 4 The PEP/LVET ratio in the same subjects.

which the values progressively decrease, though the tenth day value of $0.36 \mathrm{I}$ is still significantly higher $(P<0.001)$. The mean PEP/LVET ratios of 0.296 at rest and 0.334 with exercise of the high altitude residents are not different from those obtained in the sea level residents at sea level, but are significantly lower than the values in the latter obtained on days $I, 2$, and 3 at high altitude $(P<$ 0.001 ).

\section{Discussion}

From the data presented, it appears that healthy residents at sea level when exposed to high altitude hypoxia show evidence of left ventricular dysfunction as indicated by the systolic time intervals. There was prolongation of the pre-ejection period index (PEPI), abbreviation of the left ventricular ejection time index (LVETI), and an increase of the PEP/LVET ratio. The maximum changes in the systolic time intervals were observed on the second and third day after arrival at the altitude. These changes were greater with isometric exercise.

As patients with heart failure show similar changes in systolic time intervals (Weissler et al., 1968), it is reasonable to assume that there is definite dysfunction of the left ventricle in normal healthy sea level residents when suddenly exposed to high altitude hypoxia. The present findings are, however, not comparable to the observations of Kowalsky and Anthony (1972) who found that the PEPI shortened, LVETI increased, and PEP/LVET ratio decreased when exposed to hypobaric hypoxia. This difference could perhaps be explained by the fact that when a person is exposed for a short period of Io minutes in a hypobaric chamber, there is excessive sympathetic activity which overshadows the effects of the hypoxia.

On the other hand, in the present study, as the 20 healthy residents of sea level acted as their own controls and as there were subsequent serial observations at high altitude, both at rest and with static exercise, the validity of the findings and the significance of the changes seen in systolic time intervals appear reliable.

It is also of interest to note that in half of the subjects the resting PEP/LVET ratio and in twothirds of them the exercise PEP/LVET ratio remained significantly increased even on the tenth day. Perhaps of greater interest is the finding that the maximum increase in the PEPI, decrease in the LVETI, and increase of PEP/LVET ratio were seen on the second and third day after arrival at high altitude (especially with exercise), a vulnerable period when the maximum incidence of high altitude pulmonary oedema is also seen (Singh et al., 1965).

Physiological studies (Fred et al., 1962; Hultgren et al., 1964; Penaloza and Sime, 1969; Roy et al., 1969; Bhatia et al., 1972) have shown that these patients hyperventilate washing away the $\mathrm{CO}_{2}$, have unsaturated arterial blood, have widened alveolar-arterial $\mathrm{O}_{2}$ gradients, have low cardiac outputs and increased pulmonary arterial pressures but normal pulmonary artery wedge, left atrial mean, and left ventricular filling pressures. Specific 
tests for left ventricular function like left ventricular dp/dt or V max were not employed in these studies. However, the brachial artery mean resting $\mathrm{dp} / \mathrm{dt}$ value of $1030 \pm 243 \mathrm{mmHg}$ (136.9 \pm 32.3 $\mathrm{kPa})$ and $1227 \pm 129 \mathrm{mmHg}(163.2 \pm 17.2 \mathrm{kPa})$ with mild supine leg-raising exercise obtained in 18 healthy soldiers at sea level increased to $1308 \pm 329$ $\mathrm{mmHg}$ (173.9 $\pm 43.8 \mathrm{kPa}$ ) (resting) and $1507 \pm 27$ $\mathrm{mmHg}(200.4 \pm 3.6 \mathrm{kPa}$ ) (exercise) at $3658 \mathrm{~m}$ which led us to assume that the left ventricular function remained normal at high altitude (Roy, 1973).

The present observations, however, show definite evidence of left ventricular dysfunction as judged by systolic time intervals. It is suggested that this might be another contributory factor in the hitherto unexplained genesis of high altitude pulmonary oedema.

The authors are grateful to the Director-General Armed Forces Medical Services and his staff for their support at all phases of the study. They also wish to thank the volunteers for their co-operation and $\mathrm{Mr}$. M. A. Khan for computer programming.

\section{References}

Aronow, W. S. (1970). Isovolumetric contraction and left ventricular ejection times. External measurements at rest and after exercise in normal men. American fournal of Cardiology, 26, 238.

Bhatia, M. L., Guleria, J. S., Khanna, P. K., Manchanda, S. C., Subba, P. S., and Roy, S. B. (1972). Circulatory studies in high-altitude pulmonary oedema. In Advances in Medicine, p. 466. Ed. by R. Viswanathan. The Association of Physicians of India, Bombay.

Buyukozturk, J., Kimbiris, D., and Segal, B. L. (1971). Systolic time intervals. Relation to severity of coronary artery disease, intercoronary collateralization and left ventricular dyskinesia. American fournal of Cardiology, 28, 183.

Diamant, B., and Killip, T. (1970). Indirect assessment of left ventricular performance in acute myocardial infarction. Circulation, 42, 579.

Flessas, A. P., Kumar, S., and Spodick, D. H. (1970). Effects of the Valsalva manoeuver on the cardiac systolic intervals: beat-to-beat versus timed analysis. American Heart fournal, 80, 522.

Fred, H. L., Schmidt, A. M., Bates, T., and Hecht, H. H. (1962). Acute pulmonary edema of altitude: clinical and physiological observations. Circulation, 25, 929.

Hultgren, H. N., Lopez, C. E., Lundberg, E., and Miller, H. (1964). Physiologic studies of pulmonary edema at high altitude. Circulation, 29, 393.

Khanna, P. K., Shah, P. M., Kramer, D. H., Schaefer, R. A., and Tager, I. (I973). Effects of altered preload on left ventricular systolic time intervals in acute myocardial infarction. British Heart fournal, 35, 1102.

Kowalsky, N. B., and Anthony, J. R. (I972). Cardiac electromechanical time intervals as indices of hypoxic circulatory stress in man. Aerospace Medicine, 43, 36r.

Lindquist, V. A. Y., Spangler, R. D., and Blount, S. G. (1973). A comparison between the effects of dynamic and isometric exercise as evaluated by the systolic time intervals in normal man. American Heart fournal, 85, 227.

Moskowitz, R. L., and Wechsler, B. M. (1965). Left ventricular ejection time in aortic and mitral valve disease. American fournal of Cardiology, 15, 809.

Penaloza, D., and Sime, F. (1969). Circulatory dynamics during high altitude pulmonary edema. American fournal of Cardiology, 23, 369.

Perloff, J. K., Talano, J. V., and Ronan, J. A. (197I). Noninvasive techniques in acute myocardial infarction. Progress in Cardiovascular Diseases, 13, 437.

Pigott, V. M., Spodick, D. H., Rectra, E. H., and Khan, A. H. (1971). Cardiocirculatory responses to exercise: physiologic study by non-invasive techniques. American Heart fournal, 82, 632.

Roy, S. B. (1973). Circulatory and Ventilatory Effects of High Altitude Acclimatization and Deacclimatization of Indian Soldiers, p. 19. General Printing Company, Delhi.

Roy, S. B., Guleria, J. S., Khanna, P. K., Manchanda, S. C., Pande, J. N., and Subba, P. S. (1969). Haemodynamic studies in high altitude pulmonary oedema. British Heart fournal, 31, 52.

Siegel, W., Gilbert, C. A., Nutter, D. O., Schlant, R. C., and Hurst, J. W. (1972). Use of isometric handgrip for the indirect assessment of left ventricular function in patients with coronary atherosclerotic heart disease. American Fournal of Cardiology, 30, 48.

Singh, I., Kapila, C. C., Khanna, P. K., Nanda, R. B., and Rao, B. D. P. (1965). High-altitude pulmonary oedema. Lancet, I, 229.

Spodick, D. H., Dorr, C. A., and Calabrese, B. F. (1969). Detection of cardiac abnormality by clinical measurement of left ventricular ejection time. Fournal of the American Medical Association, 209, 239.

Weissler, A. M., and Garrard, C. L., Jr. (I97I). Systolic time intervals in cardiac disease. Modern Concepts of Cardiovascular Disease, 40, $\mathrm{r}$.

Weissler, A. M., Harris, W. S., and Schoenfeld, C. D. (1968). Systolic time intervals in heart failure in man. Circulation, 37, 149.

Weissler, A. M., Harris, W. S., and Schoenfeld, C. D. (1969). Bedside technics for the evaluation of ventricular function in man. American fournal of Cardiology, 23, 577.

Weissler, A. M., Kamen, A. R., Bornstein, R. S., Schoenfeld, C. D., and Cohen, S. (1965). The effect of deslanoside on the duration of the phases of ventricular systole in man. American fournal of Cardiology, 15, 153.

Weissler, A. M., and Schoenfeld, C. D. (1970). Effect of digitalis on systolic time intervals in heart failure. American fournal of the Medical Sciences, 259, 4.

Requests for reprints to Professor Sujoy B. Roy, Department of Cardiology, All India Institute of Medical Sciences, Ansari Nagar, New Delhi-r6, India. 